\title{
Yttrium Geothermometry Applied to Garnets from Different Metamorphic Grades Analysed by EPMA and $\mu$-PIXE Techniques
}

\author{
Alessandro Borghi ${ }^{1,5}$, Roberto Compagnoni ${ }^{1,5}$, Roberto Cossio ${ }^{1,2}$, Lorenzo Giuntini ${ }^{3}$, \\ Mirko Massi ${ }^{3}$, Filippo Olmi ${ }^{4}$, Alba P. Santo ${ }^{5}$, and Gloria Vaggelli ${ }^{6, *}$ \\ 1 Dipartimento Scienze Mineralogiche e Petrologiche, Via V. Caluso 35, I-10125 Torino, Italy \\ 2 Dipartimento di Fisica Sperimentale, Via P. Giuria 1, I-10125 Torino, Italy \\ 3 Dipartimento di Fisica - INFN Firenze, via Sansone 1, Sesto Fiorentino, Italy \\ ${ }^{4}$ Istituto di Geoscienze e Georisorse, Via G. La Pira 4, I-50121 Firenze, Italy \\ 5 Dipartimento di Scienze della Terra, Via G. La Pira 4, I-50121 Firenze, Italy \\ ${ }^{6}$ Istituto di Geoscienze e Georisorse, Via V. Caluso 35, I-10125 Torino, Italy
}

Received May 26, 2005; accepted November 25, 2005; published online April 28, 2006

(C) Springer-Verlag 2006

\begin{abstract}
We present a multi-analytical and multiinstrumental approach to a petrologic study of garnets from metapelites characterized by different metamorphic grades. The comparison between major, minor and trace element $(\mathrm{Y})$ distribution in garnets crystallized at different temperatures was performed by electron microprobe (EDS and WDS) and the Proton Induced $\mathrm{X}$-ray Emission microprobe ( $\mu$-PIXE).

Two garnet samples were selected from metapelite rocks at different metamorphic grades from the tectonic unit of Stilo, Calabrian-Peloritanian Arc, Southern Italy. Quantitative spot analysis profiles and compositional X-ray maps of major elements and yttrium are reported.

The major element zoning of garnets is mostly characterized by a smoothed and gradual concentric variation of all elements from core to rim. The Y concentration reveals a marked zoning with its distribution decreasing from about $7000 \mathrm{ppm}$ to about $100 \mathrm{ppm}$ from core to rim, respectively. The precise determination of the $\mathrm{Y}$ content by $\mu$-PIXE technique allowed us to better define the rock thermal history, by applying
\end{abstract}

\footnotetext{
* Author for correspondence. E-mail: vaggelli@igg.cnr.it
}

the Y geothermometer. In particular, a common starting temperature of about $450{ }^{\circ} \mathrm{C}$ was calculated for the beginning of the garnet growth from all over the unit, but different temperatures in the range from $520^{\circ} \mathrm{C}$ to $670^{\circ} \mathrm{C}$ were estimated for the peak event in garnets from different areas, in agreement with the $\mathrm{P}-\mathrm{T}$ values given by the main rock mineral assemblages, reflecting a different metamorphic grade.

Key words: Garnet; EPMA; $\mu$-PIXE; Y geothermometer; CalabrianPeloritan Arc.

The chemical composition of rock-forming minerals reflects their crystallisation history and provides information on the temperature and pressure conditions during their formation.

Among metamorphic minerals, garnet $[(\mathrm{Fe}, \mathrm{Mg}$, $\mathrm{Ca}, \mathrm{Mn})_{3} \mathrm{Al}_{2} \mathrm{Si}_{3} \mathrm{O}_{8}$ ] provides information because its chemical zoning records the changes in the $\mathrm{P}-\mathrm{T}$ history of the host rock [1] if the mineral assemblage in equilibrium with garnet is completely understood.

In the past, only major element compositions were determined by EPMA. However, at high temperature the growth zoning marked by major elements may be significantly modified by intra-crystalline diffusion 
[2]. Consequently, the study, in zoned garnet, of trace elements which are less susceptible to diffusion [3-5], becomes of paramount importance to reconstruct the $\mathrm{P}-\mathrm{T}$ paths in metamorphic rocks. In recent studies, the trace element zoning in garnet has been demonstrated to be highly sensitive to $\mathrm{P}-\mathrm{T}$ changes during the metamorphic history. In particular, Pyle and Spear [6] calibrated a geothermometer based on the Y content in garnet in the presence of a buffering phase (i.e. xenotime), which assures that the maximum amount of $\mathrm{Y}$ is only a function of temperature and it decreases with increasing $\mathrm{T}$.

In this paper, the utility and sensitivity of the yttrium geothermometer, in a xenotime saturated mineralogical assemblage, was checked in garnets from metapelites selected from different portions of the Stilo Unit, a coherent tectonic nappe exposed in the Calabrian-Peloritanian Arc of Southern Italy, which is characterized by a metamorphic grade gradually changing from low to medium-high.

A comparison between major and trace element distribution in garnets has been performed by electron microprobe (EDS-WDS) system and the proton induced X-ray emission, $\mu$-PIXE, facility.

The major advantage of the $\mu$-PIXE proton microprobe with respect to the electron microprobe lies in its much lower X-ray background, which makes possible to analyse element contents as low as about $10 \mathrm{ppm}$ with resolution of a few micrometers. This technique has, therefore, great potential in the solution of petrological problems, although it has rarely been applied by the Earth's scientists [7, 8].

\section{Experimental}

The petrographic study of rock sections, about $100 \mu \mathrm{m}$ thick, allowed the selection of garnet crystals with suitable microstructure for probing. This study was followed by SEM back scattered electron (BSE) imaging and by qualitative X-ray compositional mapping to identify the sites most suitable for EPMA and $\mu$-PIXE analyses. Two garnet crystals were selected from garnet-bearing metapelites collected from the lowest (Sample AC49) and highest (Sample AC50) grade parts of the Stilo unit, respectively. Major and minor elements were analyzed by EPMA along a suitable rim-core-rim profile. Finally, the same selected profiles were investigated for trace element (Y) determination by the $\mu$-PIXE mapping facility which produced long scanned stripes with a pre-selected width and length.

\section{WDS Microprobe}

Major element concentrations were determined with a JEOL-JXA 8600 superprobe equipped with four WDS's. The analytical conditions were: $15 \mathrm{kV}$ accelerating voltage, $10 \mathrm{nA}$ beam cup current, and $20 s$ acquisition times for both peaks and backgrounds. The
ZAF matrix correction was made by the TN-5600 Tracor-Northern software package. Natural silicate minerals were used as primary standards.

\section{Micro-PIXE Facility}

The external proton microprobe facility, placed on a beam line of the new $3 \mathrm{MV}$ Tandetron accelerator at the LABEC laboratory of INFN in Florence was used. The Tandetron accelerator options are: an optical microcamera system which shows areas of about $1 \mathrm{~mm}^{2}$ on a TV screen; a combined beam-scanning and sample-movement up to $25 \times 25 \mathrm{~mm}^{2}$; $\mathrm{Si}(\mathrm{Li})$ and Ge detectors; a Backscattering Spectroscope (BS), and a Particle Induced Gamma-ray Emission (PIGE) equipment.

The analytical conditions used were: beam energy of $3 \mathrm{MeV}$; current of $1.5 \mathrm{nA}$; target ( $2 \mathrm{~mm}$ out of the exit window); He flow; spot size of $\sim 10 \mu \mathrm{m}$ FWHM; acquisition time of $90 \mathrm{~min}$ at counts rate of about $2000 \mathrm{cps}, \mathrm{Si}(\mathrm{Li})$ solid angle of $0.1 \mathrm{msr}$, absorber layer for Ge: Mylar foils $620 \mu \mathrm{m}$ thick $+\mathrm{Al}$ foils $25 \mu \mathrm{m}$ thick. The detectors were positioned at $\sim 135^{\circ}$ to the beam. Beam current monitoring: Si X-ray yield of $\sim 700$ counts per $\mathrm{nC}$.

The dynamic analysis was used to estimate the Y content according to the standard-less PIXE analysis method developed at the CSIRO and by using the GeoPIXE II software package [9], http:// www.nmp.csiro.au/GeoPIXE.html.

In a typical PIXE spectrum scanned over an area of different minerals there are numerous element overlaps. Using pure element line-shapes signatures the spectrum can be least-squares fitted rather accurately. The peak areas in the spectrum can be thought as linear combinations of the elemental signatures [10].

We could solve the resulting set of linear simultaneous equations, expressed as a matrix equation, to obtain elemental concentrations. This could be done by matrix inversion. The inverse matrix would then become a transform from peak area to elemental concentration. Using this matrix, every X-ray event can then be transformed as it occurs to build pure element images, free of overlap artefacts, in real-time.

Since this method strongly reject artefacts due to overlapping elements, detector effects (such as escape peaks and tailing) and background, images, by means of standard-less PIXE analysis method developed at the CSIRO for the quantitative analysis of PIXE spectra, are then quantitative and stored in ppm-charge units [11].

\section{Results and Discussions}

The study on zoned garnet crystals, grown at different pressure and temperature conditions and occurring in xenotime saturated metamorphic rocks from the "Stilo Unit" of the Calabrian-Peloritanian Arc, is here reported.

The pressure and temperature evolution with time of the host rocks are independently constrained by the mineralogical reactions and conventional thermobarometric estimates based on cationic exchanges of major elements between garnet and other $\mathrm{Fe}-\mathrm{Mg}$ phases [12].

\section{Geologic and Petrologic Framework}

The Stilo unit is a coherent portion of a mono-metamorphic Variscan basement, locally intruded by post- 

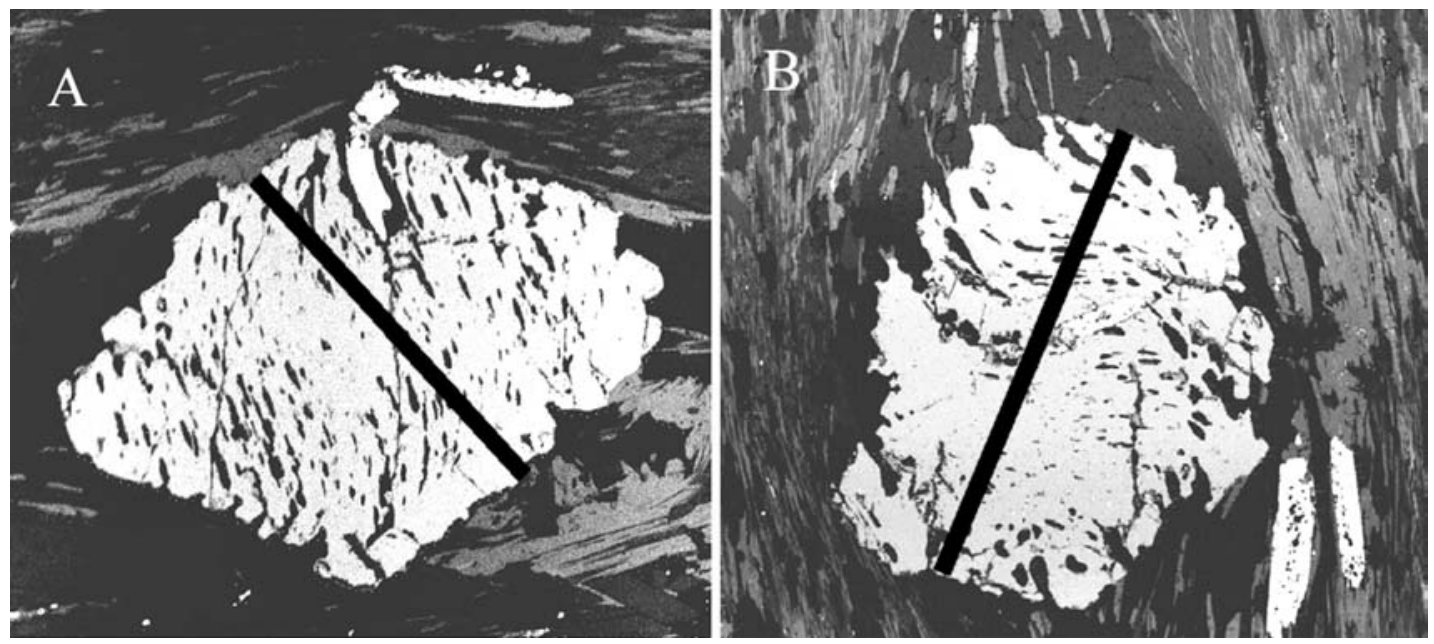

Fig. 1. S.E.M. backscattered electron (BSE) images of garnets AC50 (A) and AC49 (B). Black thick line: rim-core-rim profile of the garnet points analyzed by EPMA and $\mu$-PIXE. (Black line length $A=0.6 \mathrm{~mm} ; \mathrm{B}=1 \mathrm{~mm}$ )

Variscan granitoids and overlain by a Mesozoic sedimentary cover [13, 14]. The metamorphic basement exhibits a significant regional metamorphic zoning from very-low-grade phyllite to amphibolite-facies micaschist and paragneiss. Five metamorphic zones, with increasing metamorphic grade, were distinguished by a detailed field and petrologic study. The recognised metamorphic zones are characterised by the following main mineral assemblages (listed by increasing metamorphic grade): chlorite-quartz-white mica (Zone A); chlorite-quartz-white mica-biotite (Zone B); garnet + chlorite (Zone C); garnet + biotite (Zone D); garnet + biotite \pm staurolite \pm andalusite \pm cordierite (Zone E). The higher-grade zones C, D and E contain garnet as ubiquitous stable mineral phase. The studied garnets AC50 and AC49 have been selected from metapelites of zones $\mathrm{C}$ and $\mathrm{E}$, respectively. Both garnets are porphyroblasts $1-2 \mathrm{~mm}$ in diameter. As evident from the BSE images (Fig. 1A and B), the two garnets show an internal sigmoid foliation, defined by trails of small quartz inclusions in continuity with the external foliation: this suggests that garnets grew syn-kinematically, with respect to the related tectono-metamorphic event.

The zone $\mathrm{C}$ metapelite is a fine-grained phyllite consisting of quartz + white mica + chlorite + albite + subordinate garnet assemblage, syn-kinematic with respect to the development of the main regional foliation. Biotite also occurs as random post-kinematic flakes considered to be developed during a slight $\mathrm{T}$ increase. This phyllite shows a prograde metamorphic evolution characterized by a thermal peak under greenschist facies conditions, estimated at $\mathrm{T}=500-550^{\circ} \mathrm{C}$ on the base of the mineral assemblage. Temperatures in the range $515-540^{\circ} \mathrm{C}$ were obtained by applying the biotite-garnet $\mathrm{Fe}-\mathrm{Mg}$ exchange geothermometer $[15,16]$.

The zone E metapelite consists of quartz, white mica, biotite, plagioclase and minor garnet (with xenotime inclusions), andalusite, cordierite and chlorite. This rock displays a more complex metamorphic evolution, characterized by the presence of relics of a greenschist-facies metamorphic event, similar to that recorded by the zone $\mathrm{C}$ metapelite (i.e. quartz, white mica, chlorite, Na-plagioclase and garnet), pervasively overprinted by a second event with andalusite + cordierite + Ca-plagioclase + garnet, developed under prograde amphibolite-facies conditions. However, garnet-biotite geothermometric estimates for the metamorphic peak of the second event yield a temperature lower than $550^{\circ} \mathrm{C}$, which is too low since incompatible with the pervasive amphibolite-facies assemblage.

\section{AC50 Garnet Composition}

The four major elements $\mathrm{Mg}, \mathrm{Ca}, \mathrm{Mn}, \mathrm{Fe}$, characterizing the garnet zoning, have been determined by WDS spot analyses (Table 1) along the profile reported in Fig. 1A.

Garnet AC50 displays a relatively flat major elements pattern with a slight $\mathrm{Fe}$-increase and $\mathrm{Mn}$-decrease in the rim (Fig. 2a).

The Y profile (Fig. 3a) shows a marked compositional variation, characterized by a large core with a slight oscillatory zoning in the range 6000-7200 ppm 


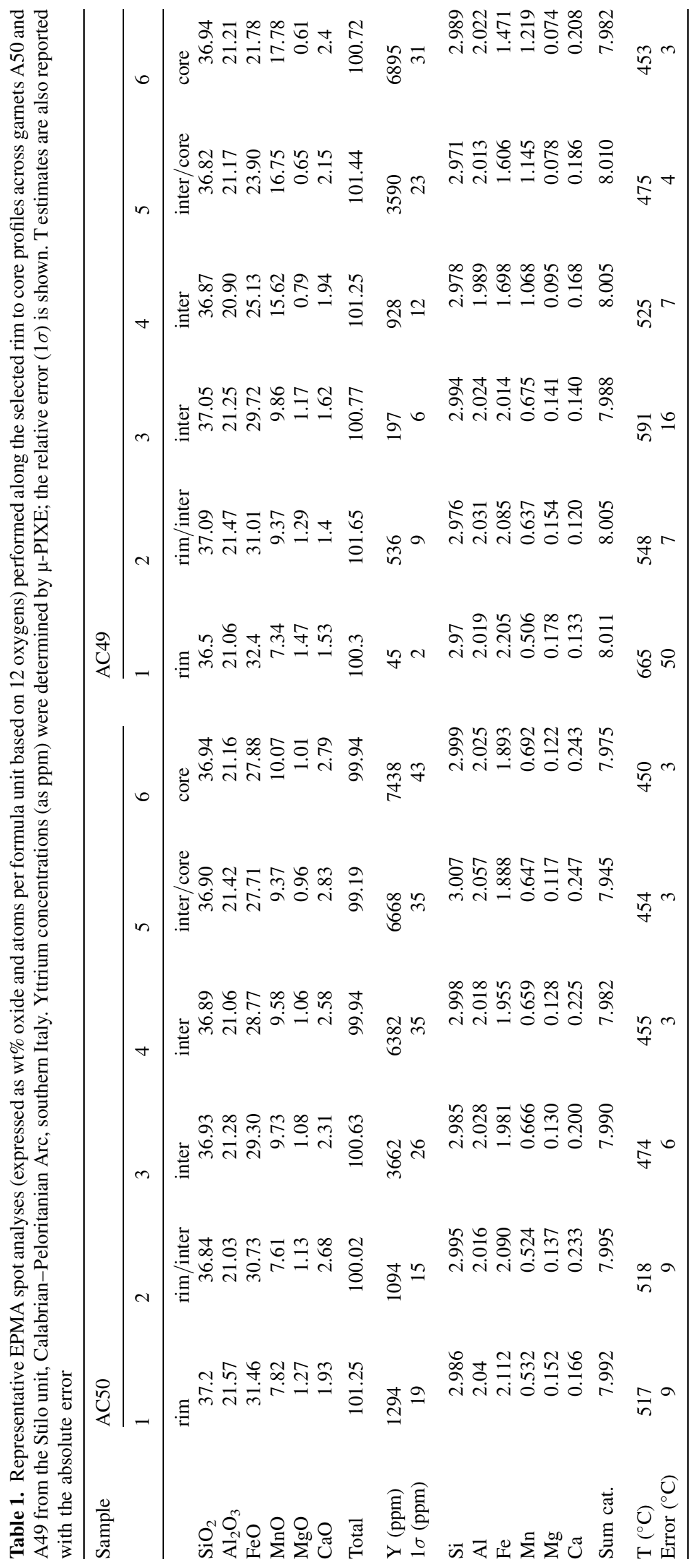



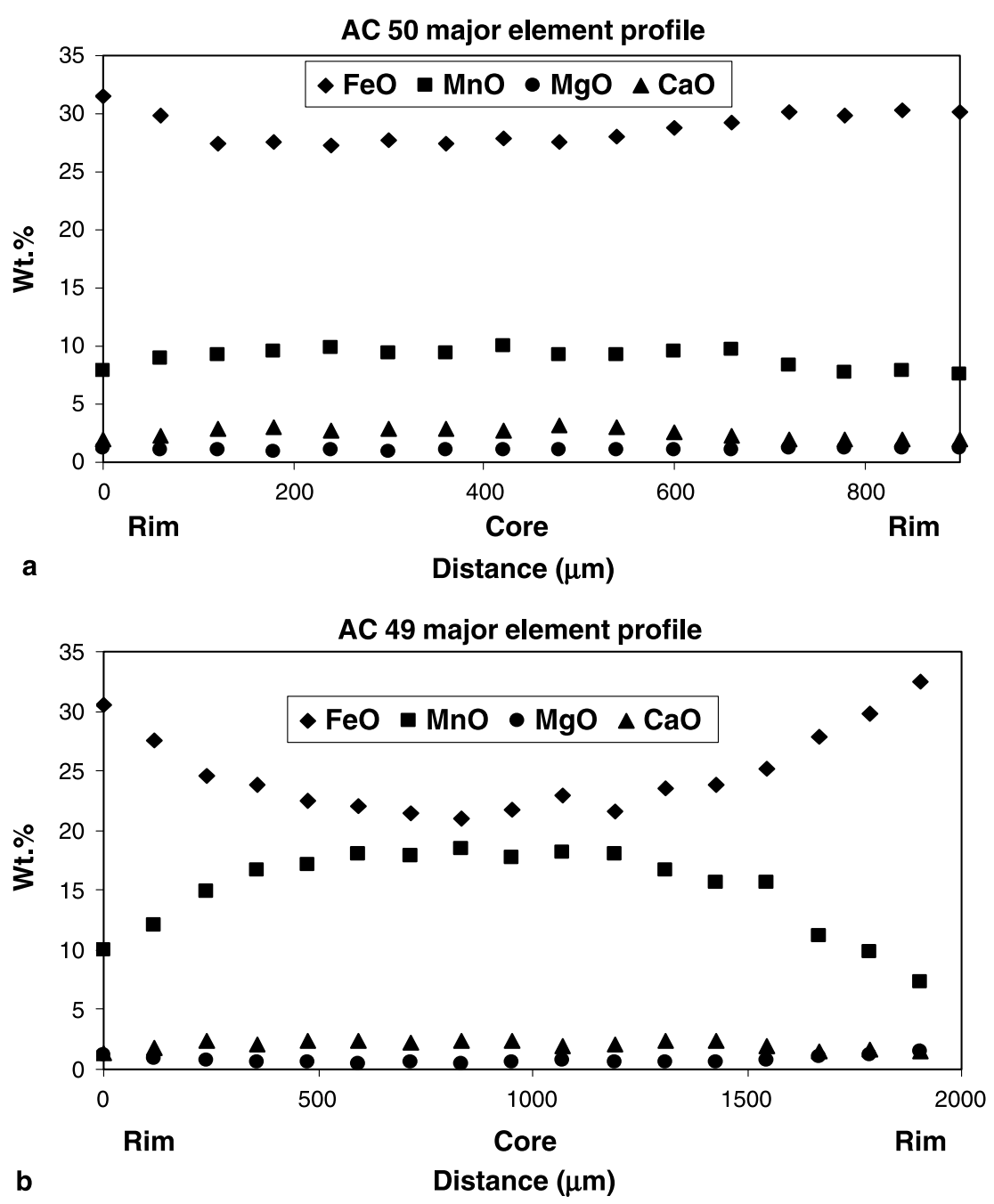

Fig. 2. Concentrations of $\mathrm{Fe}, \mathrm{Mn}, \mathrm{Mg}$ and $\mathrm{Ca}$ (as wt $\%$ oxides) determined by WDS EPMA along the representative rim-corerim profile of garnets AC50 (a) and AC49 (b) and a thin rim, about $150 \mu \mathrm{m}$ thick, with a sharp decrease in the $\mathrm{Y}$ content down to about $1000 \mathrm{ppm}$. This rim has been interpreted as a second garnet generation overgrown during a moderate $\mathrm{T}$ increase, also suggested by the antipathetic $\mathrm{Fe}$ and $\mathrm{Mn}$ variations in the garnet rim and the occurrence of static biotite.

The temperature distribution estimated from Y zoning is characterized by a flat pattern in the central crystal portion and by a slight increase in the rim. By applying the Y geothermometer [6], the metamorphic temperature estimates were calculated and reported in Fig. 3b. $\mathrm{T}=450 \pm 5^{\circ} \mathrm{C}$ using the core concentrations of about $7000 \mathrm{ppm}$ and $\mathrm{T}=520 \pm 10^{\circ} \mathrm{C}$ using the rim concentrations of $1100 \mathrm{ppm}$ were obtained, respectively. The analytical error is extremely low $\left(<5^{\circ} \mathrm{C}\right)$ for the core and wider for the rim (Fig. 3b), because of the logarithmic relationship between $\mathrm{T}$ and $\mathrm{Y}$ concentration [6]. The flat $\mathrm{Y}$ profile indicates that metamorphic temperatures remained constant during most of the garnet growth, and slightly increased only at the end of the garnet crystallization path (Fig. 3b). The estimated $\mathrm{T}$ values are in agreement both with the petrographic mineral compatibilities and minerochemical data, which indicate a simple metamorphic evolution with a $\mathrm{T}$ peak under greenschist-facies conditions, i.e. in the range $500-550{ }^{\circ} \mathrm{C}$. Therefore, the conventional garnet-biotite $\mathrm{Fe}-\mathrm{Mg}$ exchange geothermometer, based on major element concentrations, gives results consistent with those obtained from the $\mathrm{Y}$ geothermometer. This indicates that during the growth of garnet AC50, the diffusion rate of major elements was very slow and in any case unable to homogenize them.

\section{AC49 Garnet Composition}

The concentrations of the four major elements, $\mathrm{Mg}$, $\mathrm{Ca}, \mathrm{Mn}, \mathrm{Fe}$, in garnet $\mathrm{A} 49$ (Table 1) along the rim to 

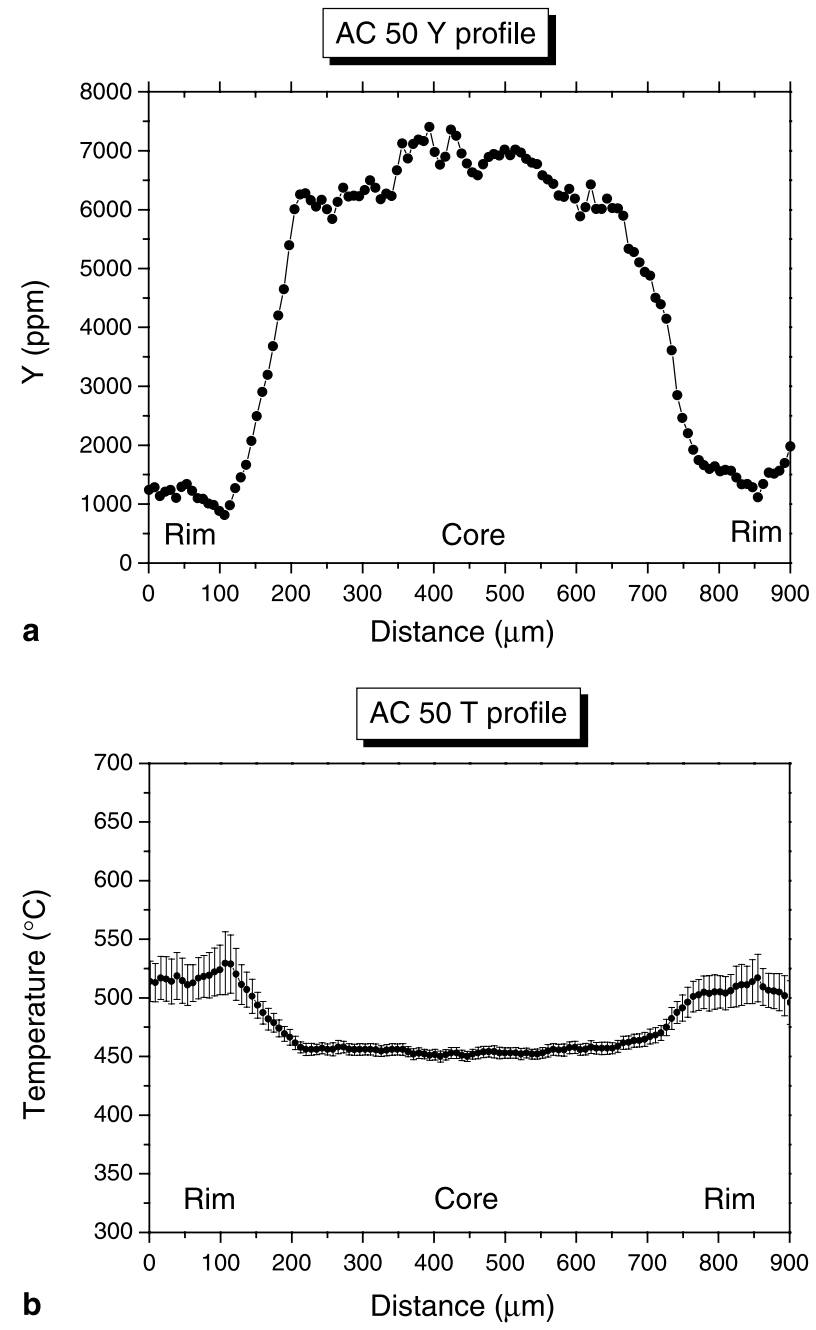

Fig. 3. (a) Concentrations of $\mathrm{Y}$ acquired by $\mu$-PIXE facility along the representative rim-core-rim profile of garnet AC50. (b) Metamorphic temperatures estimated from the Y geothermometer [6] along the rim-core-rim garnet profile shown above. For each analysis the analytical error is also reported as $1 \sigma$

core to rim profile reported in Fig. 1B were determined by EPMA.

Garnet AC49 shows a well defined symmetrical compositional zoning, characterised by a smoothing and gradual variation in the concentration of four determined major elements (Fig. 2b, Table 1). In particular, $\mathrm{FeO}$ and $\mathrm{MgO}$ increase, whereas $\mathrm{MnO}$ and $\mathrm{CaO}$ decrease from core to rim, respectively. This element pattern is consistent with a growth zoning developed under low to medium $\mathrm{T}$ metamorphic conditions [2].

The quantitative $\mu$-PIXE profile shows a marked Y peak in the garnet core surrounded by a lower and flat pattern (Fig. 4a). The Y abundance varies of two orders of magnitude from almost $6900 \mathrm{ppm}$ in the core to about
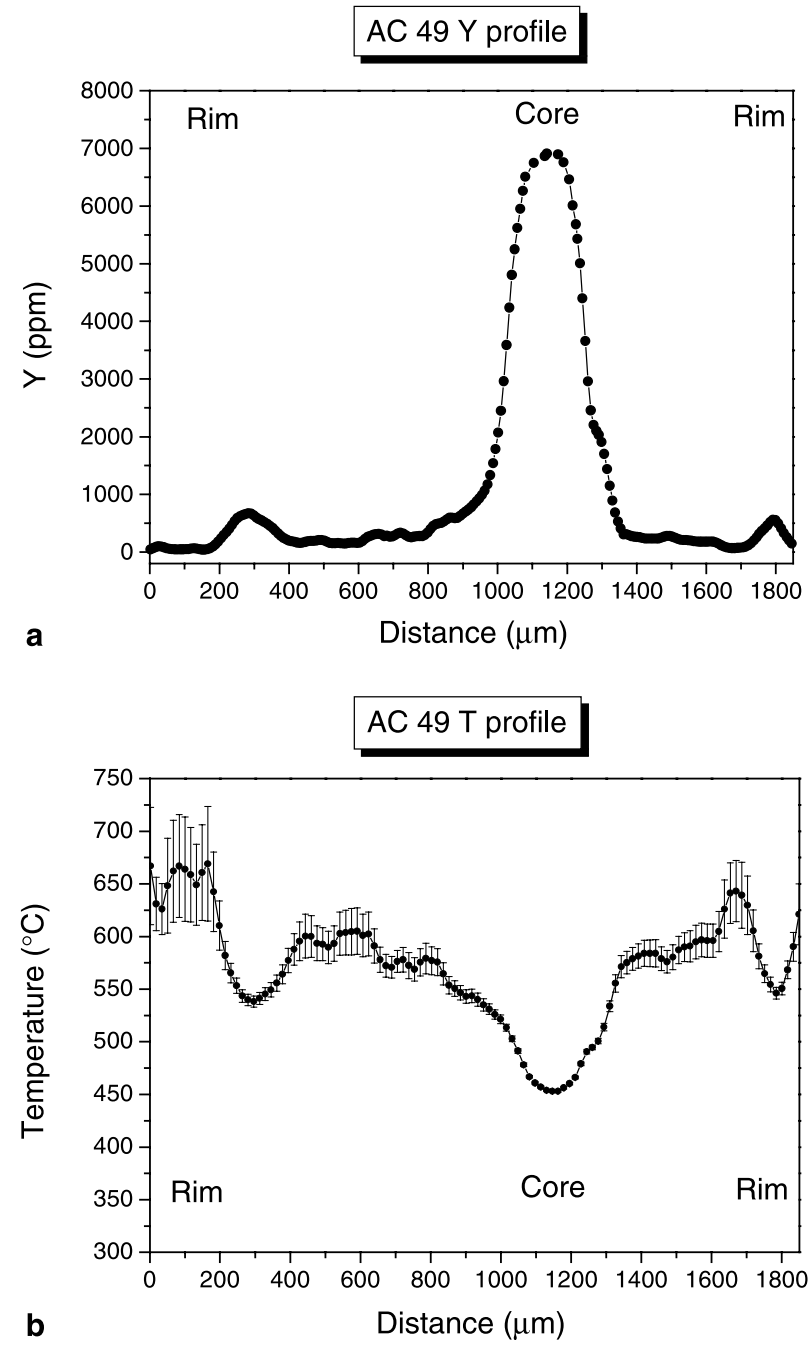

Fig. 4. (a) Concentrations of $Y$ acquired by $\mu$-PIXE facility along the representative rim-core-rim profile of garnet AC49. (b) Metamorphic temperatures estimated from the $\mathrm{Y}$ geothermometer [6] along the rim-core-rim garnet profile shown above. For each analysis the analytical error is also reported as $1 \sigma$

$50 \mathrm{ppm}$ in the rim. This pattern is in agreement with the results reported by [17] for metapelite garnets from low to medium grade metamorphic conditions. The shape of the $\mathrm{Y}$ concentration pattern, therefore, implies prograde metamorphic conditions characterized by a progressive temperature increase during the garnet growth. The $\mathrm{Y}$ profile also shows two small symmetrical peaks at about $250 \mu \mathrm{m}$ from the crystal edges, suggesting the presence of an anomalous higher- $\mathrm{Y}$ annulus. This kind of oscillatory zoning may be explained as the result of a garnet resorption coupled with a back-diffusion of $\mathrm{Y}$ into the garnet crystal, followed by its reincorporation during the overgrowth of a new garnet generation with different composition $[18,19]$. 
Comparing the sharp $\mathrm{Y}$ pattern with the smooth profiles shown by major elements (Figs. $2 b$ and $4 a$ ), it is clear the difference in the diffusion rates between major and trace elements. This difference accounts for the preservation of the original $\mathrm{Y}$ zoning pattern, which can be used to reconstruct the thermal history of the host rock.

By applying the $\mathrm{Y}$ geothermometer [6], a $\mathrm{T}$ of $450 \pm 5^{\circ} \mathrm{C}$ was estimated from the core $\mathrm{Y}$ concentration of about $6900 \mathrm{ppm}$ (Fig. 4b), whereas progressively increasing temperatures, up to a peak value of $670 \pm 10^{\circ} \mathrm{C}$ from the $\mathrm{Y}$ concentration of $50 \mathrm{ppm}$ of the garnet rim, were obtained.

It is interesting to note that, applying the $\mathrm{Y}$ geothermometer, the core temperature estimated from garnet AC49 is comparable to the core temperature estimated from garnet AC50 (Fig. 5a, b). This suggests that the two studied garnets started to grow at similar $\mathrm{T}$ conditions, but while garnet AC50 underwent a moderate $\mathrm{T}$ increase still within greenschist facies conditions, garnet AC49 experienced a more complex prograde metamorphic evolution up to amphibolitefacies conditions $\left(\mathrm{T}_{\max }=670^{\circ} \mathrm{C}\right)$. It has to point out that for sample AC49 the conventional geotherm-
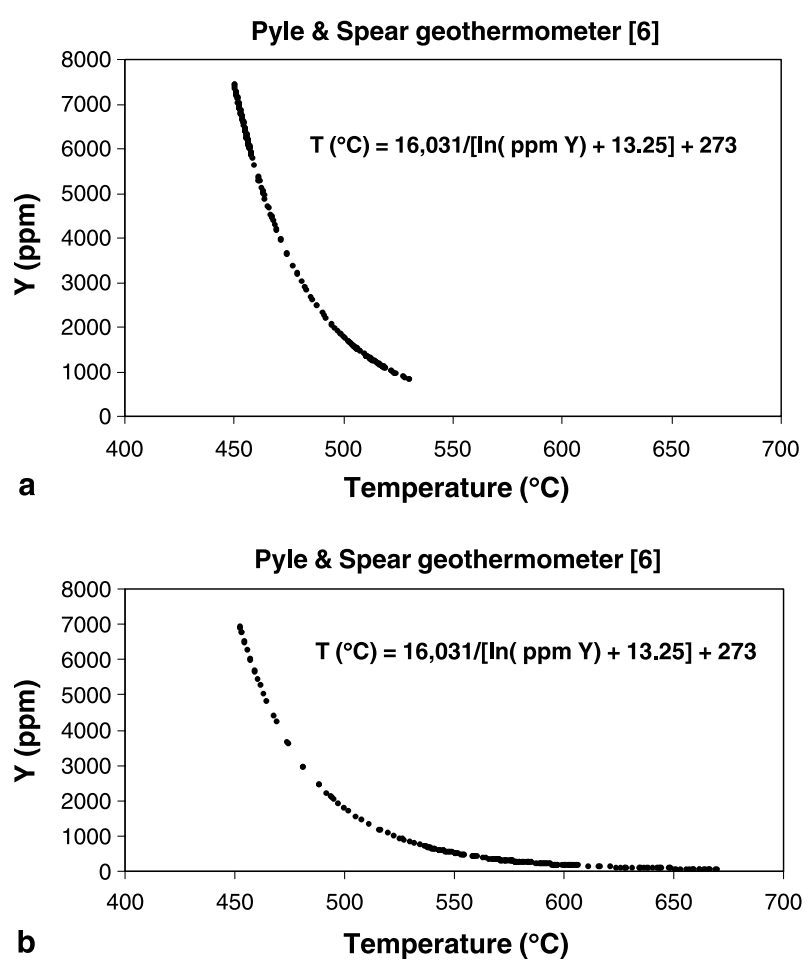

Fig. 5. Estimated Temperatures calculated from the equation of Pyle \& Spear [6] using the concentration profiles for garnet AC50 (a) and garnet AC49 (b), respectively ometers, based on major element exchange, do not record the real metamorphic peak $\mathrm{T}$, because the major elements have been significantly affected by diffusion processes.

\section{Conclusion}

Applying a combined electron/proton-beam techniqueapproach to a specific petrological problem, it has been possible to determine the true temperature conditions at which a metamorphic rock re-equilibrated. In particular, this study indicates that the $\mu$-PIXE technique is of paramount importance in solving petrologic problems, where the accurate determination of very low trace element concentrations is essential, such as the $\mathrm{T}$ estimates by applying the $\mathrm{Y}$ geothermometer [6]. This study has shown that the Y geothermometer may supply otherwise unavailable information on the P-T history. However, the sensitivity of this geothermometer is decreasing with the T-increase, since the $\mathrm{Y}$ incorporation into garnet has a logarithmic correlation with $\mathrm{T}$. Therefore, for $\mathrm{T}$ values higher than $600^{\circ} \mathrm{C}$, small variations of $\mathrm{Y}$ imply large variations in the temperature estimates.

The study of garnets from rocks samples, which experienced different metamorphic evolutions and peak $\mathrm{T}$, confirms that the $\mathrm{Y}$ content in garnet is actually T-dependent.

Finally, the slow diffusion rate of $\mathrm{Y}$ in garnet allows one to recognize petrogenetic events which are not recorded by major elements, due to their much higher diffusion rate.

Acknowledgements. Financial support by Ministero dell'Istruzione, dell'Università e della Ricerca (M.I.U.R) and by Consiglio Nazionale delle Ricerche (C.N.R.), Istituto di Geoscienze e Georisorse: projects 2004-2005. G. Pratesi (University of Firenze) is thanked for Geopixe licence providing. Two anonymous referees are acknowledged for constructive comments.

\section{References}

[1] Borghi A, Cossio R, Olmi F, Vaggelli G (1998) Mikrochim Acta 15: 227

[2] Spear F S (1989) Evolution of metamorphic belts. In: Daly J F, Cliff R A, Yardley B W D (eds) Geological Society of London, Special publication 43: 63

[3] Ganguly J, Tirone M, Hervig R L (1998) Science 281: 607

[4] Tirone M, Ganguly J, Dohmen R, Langenhorst F, Hans R (2004) Geochim Cosmochim Acta 69: 2385

[5] Chakraborty S, Ganguly J (1992) Contrib Mineral Petrol 111: 74

[6] Pyle J M, Spear F S (2000) Contrib Mineral Petrol 138: 51

[7] Fraser D G (1990) Chemical Geology 83: 27 
[8] Sie S H (1993) Nucl Instr Meth B75: 403

[9] Ryan C G, Jamieson D N (1993) Nucl Instr Meth B77: 203

[10] Ryan C G, Van Achterbergh E, Mark G, Yeats C J, Drieberg S L, McInnes B M, Win T T, Cripps G, Suter G F (2002) Nucl Instr Meth B188: 18

[11] Ryan C G, van Achterbergh E, Yeats C J, Tin Tin Win, Cripps G (2002) Nucl Instr Meth B 189: 400

[12] Graessner T, Schenk V (1999) J Metamorph Geol 17(2): 157
[13] Bonardi G, Messina A, Perrone V, Russo S, Zuppetta A (1984) Boll Soc Geol It 103: 279

[14] Crisci G M, Messina A, Russo S, Perrone V (1982) Rend Soc It Miner Petrol 38: 989

[15] Ferry J M, Spear F S (1978) Contrib Mineral Petrol 66: 113

[16] Kleemann U, Reinhardt J (1994) Eur J Mineral 6: 925

[17] Pyle J M, Spear F S (1999) Geol Mat Res 61

[18] Lanzirotti A (1995) Geochim Cosmochim Acta 59: 4105

[19] Chernoff C B, Carlson W D (1999) Geology 27: 555 